\title{
Energy Efficiency Analysis Using Pinch Technology: A Case Study of Orbit Chemicals Industry
}

\author{
MusonyeShombe Fenwicks ${ }^{1}$, Kinyua, Robert ${ }^{2}$ and Aganda, Alex ${ }^{3}$. \\ ${ }^{1}$ Institute of Energy and Environmental Technology, JKUAT, Nairobi, Kenya \\ ${ }^{2}$ Institute of Energy and Environmental Technology, JKUAT, Nairobi, Kenya \\ ${ }^{3}$ Department of Mechanical Engineering, University of Nairobi, Nairobi, Kenya.
}

\begin{abstract}
The rising cost of fossil fuels and their negative impact to the environment has made it necessary for manufacturing industry to reduce energy consumption. Energy audits are commonly used to improve energy efficiency. However, the audits do not usually involve in-depth analysis of design features for optimum energy use. Pinch technology analysis, which involves heat exchanger design and retrofits, is increasingly being used to optimize energy utilization especially in thermo-chemical industries. Various pinch analysis studies have been conducted in different manufacturing and processing plants. However, there is no published literature about pinch analysis studies in the sulphonation process. Presented in this paper is the application of the pinch technology analysis to a sulphonation process at Orbit Chemical industries- Nairobi. The aim was to design a heat exchanger network retrofit for energy use reduction in the sulphonation process and to develop an investment appraisal for the design.
\end{abstract}

The sulphonation plant studied consisted of 11 process streams. 3 streams went through heating processes and 8 streams went through cooling processes. The heating streams involved melting sulphur and raising its temperature to $160^{\circ} \mathrm{C}$ and generating steam at two temperatures $203^{\circ} \mathrm{C}$ and $160^{\circ} \mathrm{C}$. The cooling streams involved cooling of air $\left(203^{\circ} \mathrm{C}-8^{\circ} \mathrm{C}\right), \mathrm{SO}_{2}\left(568.3^{\circ}-527.3^{\circ} \mathrm{C}\right), \mathrm{SO}_{3}\left(527.3-451.7,584.7-451,483.7-460^{\circ} \mathrm{C}\right)$, $\left(456.3-202.8^{\circ} \mathrm{C}, 198.6-28.3^{\circ} \mathrm{C}\right)$, LABSA $\left(29-24^{\circ} \mathrm{C}\right)$.

The heat exchanger network design resulted into a retrofit of 7 heat exchangers. If the retrofit could be implemented, the required external heating load could be reduced from $2.772 \mathrm{MW}$ to $2.456 \mathrm{MW}$ and the external cooling load from $0.329 \mathrm{MW}$ to $0.014 \mathrm{MW}$. The recoverable heat was found to be $0.316 \mathrm{MW}$ with estimated saving of $11.4 \%$. The annual savings for this design were KShs 3132 093. The cost of retrofit was estimated at a current cost of KShs 49275540 with a simple payback period of 14 years.

Key Words: Energy Consumption, Energy Efficiency, Pinch Technology, Heat Exchanger Network Retrofit, Investment Appraisal, Thermo-Chemical Industries, Sulphonation.

\section{Introduction}

The demand for energy in the industrial sector has been increasing, causing a rise in the cost of energy and cost of production. Alongside the increased cost of production, increased use of fossil fuels threatens to increase the amount of carbon dioxide in the atmosphere. Engineers and other stakeholders in the industrial sector have a task to reduce the demand for energy. Reduced demand will cause reduced cost of production and reduced emission of carbon dioxide into the atmosphere. Petrochemical industries, cement factories, oil refineries, steel mills, paper pulp mill industries and other plants that involve thermo-chemical processes are classified as energy intensive. The industries can use different methods to reduce the demand for fossil fuel energy. The industries can use the energy efficiently or substitute the fossil fuels with renewable energy. Energy efficiency methods include the pinch analysis, emergy, exergy analysis and use of the learning curves [1]. Developing countries, like Kenya, have been at the forefront of implementing energy efficiency measures in their industrial sector. Kenya Association of Manufacturers (KAM) leads the efforts in implementation of energy saving measures in Kenya. The association uses energy audits as a tool to reduce the energy demand in the factories. Orbit 
Chemical Industries Limited is a member of KAM. It produces a detergent washing powder as one of its products. In 2012, the company carried out energy audits in all its plants. Energy audits are not sufficient to reduce the energy consumption in thermo-chemical plants. This paper presents the results of the energy efficiency studies that were carried out in the sulphonation plant of Orbit Chemical Industries Limited. The energy efficiency tool of pinch technology was used to carry out the studies.

Several studies have been carried out to improve efficiency in different energy intensive plants. Pinch technology is one of the most preferred methods of carrying out efficiency analysis and design in plants. This study takes an integrative approach to efficiency analysis. Pinch analysis has been widely used in different industrial set ups to reduce energy consumption. Reference [2] presented findings of pinch analysis in a Partly Integrated Pulp and Paper Mill in Kraft factory. In the findings, it was calculated that the potential savings for the plant was 18.5 Megawatts. This presented $12 \%$ of the steam demand. Even though the potential savings were estimated at 18.5 Megawatts, the practical savings that could be achieved in retrofit were less. Two retrofit designs were drawn. The first design was the easiest to implement and had savings of 5.8 Megawatts. The second retrofit option was more extensive and had potential of saving 11 Megawatts. The payback period for the retrofit implementation was estimated to be less than 16 months. Likewise, Reference [3] carried out pinch analysis in a thermo-mechanical pulp mill in Norske Skog Skogn. In the pinch analysis, the researchers came up with retrofit designs that could be adopted. In the first retrofit suggestion, 1.1 Megawatt of steam was recovered. This was $4 \%$ of the total steam consumption at the plant. The second retrofit suggestion recovered 2.2 Megawatts while the third retrofit suggestion recovered 2.8 Megawatts.

These studies are evident to the fact that pinch analysis can be used to obtain optimal savings in energy intensive plants. However, the two have not carried out the studies in a sulphonation plant. This research carried out the pinch analysis study to come up with the maximum energy recovery design for the sulphonation plant in Orbit Chemical Industries in Kenya. The pinch analysis process had four objectives. The first objective was to calculate the optimum energy targets in the plant. The second objective was to design a heat exchange network that would achieve the targets. The last objective was to come up with an investment appraisal for implementation of the suggested heat exchange network retrofit.

\section{The Sulphonation Process}

The sulphonation plant processes the linear alkyl benzyl sulphonic acid (LABSA). LABSA is the raw material used for production of powder detergent. Production of LABSA involves heating and cooling processes. Sulphur is heated and melted to a temperature of about $160^{\circ} \mathrm{C}$. The molten sulphur is transferred into a reaction furnace. It reacts with process air to form sulphur dioxide. The molten sulphur is lagged with steam while being transferred to the reaction furnace. The process air is cooled and dried before reacting with the molten sulphur. During the drying of the process air, steam is used for regeneration of the drying system. The sulphur dioxide is cooled and then converted into sulphur trioxide in presence of vanadium pentoxide as the catalyst. This multistage conversion process takes place in the sulphonation chamber and it is exothermic. It undergoes a three stage cooling process. After the complete conversion in the sulphonation chamber, the sulphur trioxide is transferred into another two stage cooling chamber. The cooled sulphur trioxide reacts with sulphuric acid to form oleum. Oleum reacts with linear alky benzyl to form LABSA. The LABSA is cooled and stored to use in the detergent processing plant. The entire process has three processes that require external heating loads and eight processes that require external cooling loads. 


\section{Methodology}

A survey of the processes in the sulphonation plant was carried out. The survey lasted two weeks. A sketch of the processes was drawn. The sketch assisted in identification of the areas where data was to be collected. The data was collected from the three heating loads and the seven cooling loads. Values of the initial temperature, the final temperature and the mass flow rates were recorded from each load. Latent heat of fusion, latent heat of vaporization and the specific heat capacities of the process materials were collected as secondary data from established literature. Data was collected for five days. Every day, data collected five times, on an hourly basis. The values were averaged.

The temperature values and the mass flow rates were recorded by the digital display unit in the factory control room. The temperature range that could be recorded at the display unit was between $-80{ }^{\circ} \mathrm{C}$ to $800{ }^{\circ} \mathrm{C}$. The flow meter at the display unit was calibrated in Kilograms per hour and could measure flow between 200 kilogram per hour and $6500 \mathrm{Kg}$ per hour. The obtained data was used to calculate the total heating and cooling requirements in the sulphonation plant, the energy targets and to design the heat recovery network. The cost of implementing network design was calculated and investment appraisal done using simple payback period. The cost information was obtained from the management of the factory, Energy Regulatory Commission of Kenya and the vendors of heat exchange materials.

\section{Results}

Table 4.1 presents the results of the data obtained from the heating and the cooling points of the sulphonation process. The table shows the initial temperature $T_{i}$, the final temperature $T_{f}$, the mass flow rate $\dot{m}$, the specific heat capacity at constant pressure $\mathrm{Cp}$, the heat capacity flow rate $\mathrm{Cp}$. $\dot{\mathrm{m}}$ and the rate of enthalpy change $\mathrm{Q}$ of every process. The processes have been assigned numerical values for nominal purposes as follows: 1. Heating and melting of sulphur. 2. Cooling of the process air. 3 (w). Heating and boiling the water for regeneration of the process air cooling system. 3(s). Heating and raising the temperature of the regeneration steam. 4. Cooling of sulphur dioxide. 5. First stage cooling of the sulphur trioxide in the suphonation chamber. 6. Second stage cooling of sulphur trioxide in the suphonation chamber. 7. Final stage cooling of sulphur trioxide in the suphonation chamber. 8. First stage cooling of the completely reacted sulphur trioxide. 9. Second stage cooling of the completely reacted sulphur trioxide. 10. Cooling of LABSA. 11(w). Heating of the water used to generate molten sulphur lagging steam to boiling point. 11(s) Heating and raising the temperature of the molten sulphur lagging steam.

On the table, $\mathrm{Q}=\left(\mathrm{C}_{\mathrm{p}} \times \dot{\mathrm{m}}\right) \times\left(\mathrm{T}_{\mathrm{i}}-\mathrm{T}_{\mathrm{f}}\right)$.

The negative value of $\mathrm{Q}$ denotes heating and the positive values denote cooling [1]. 
Table 4.1: Heating and Cooling Load Data

\begin{tabular}{|c|c|c|c|c|c|c|}
\hline Process & $\begin{array}{l}\text { Cp. } \\
\left(\mathbf{k J} / \mathbf{k g} .{ }^{\circ} \mathrm{C}\right)\end{array}$ & m $(\mathrm{Kg} / \mathbf{s})$ & $\begin{array}{l}\text { Cp.m. } \\
\text { (kW/ oc) }\end{array}$ & $\mathrm{T}_{\mathrm{i}}\left({ }^{\circ} \mathrm{C}\right)$ & $T_{f}\left({ }^{\circ} \mathrm{C}\right)$ & $Q(k W)$ \\
\hline 1 & 0.73 & 1.31 & 0.957 & 26 & 160 & -128.238 \\
\hline 2 & 1.013 & 0.439 & 0.445 & 203 & 8 & 86.775 \\
\hline $3 w$ & 4.18 & 0.521 & 2.178 & 26 & 100 & -161.172 \\
\hline $3 s$ & 2.09 & 0.521 & 1.089 & 100 & 203.9 & -113.147 \\
\hline 4 & 0.82 & 0.983 & 0.806 & 568.3 & 527.3 & 33.046 \\
\hline 5 & 0.9 & 0.764 & 0.688 & 527.3 & 451.7 & 51.983 \\
\hline 6 & 0.9 & 0.754 & 0.679 & 584.7 & 451 & 90.782 \\
\hline 7 & 0.9 & 0.393 & 0.354 & 483.7 & 460 & 8.39 \\
\hline 8 & 0.84 & 0.18 & 0.151 & 456.3 & 202.8 & 38.279 \\
\hline 9 & 0.71 & 0.15 & 0.107 & 198.6 & 28.3 & 18.222 \\
\hline 10 & 4.18 & 0.12 & 0.502 & 24 & 29 & 2.51 \\
\hline $11 w$ & 4.18 & 0.417 & 1.743 & 26 & 100 & -129 \\
\hline $11 \mathrm{~s}$ & 2.09 & 0.417 & 0.872 & 100 & 160 & -52.32 \\
\hline
\end{tabular}

\subsection{Energy Targeting}

From Table 4.1, the total heating and cooling requirements were computed. Process $3 \mathrm{w}$ and $11 \mathrm{w}$ involved boiling and thus absorbed the latent heat of vaporization. Process 1 involved melting. This involved absorption of latent heat of fusion. The latent heat was calculated separate from Table 4.1 as shown:

Latent heat of fusion for process 1

Specific latent heat of fusion of sulphur $\times$ Mass Flow Rate of Process $1=54 \mathrm{~kJ} / \mathrm{Kg} \times 1.31 \mathrm{Kg} / \mathrm{s}=-70.74 \mathrm{~kW}$.

Latent heat of vaporization for process $3 \mathrm{w}$

Specific latent heat of vaporization of water $\times$ Process $3 \mathrm{w}$ Mass Flow Rate $=2257 \mathrm{~kJ} / \mathrm{kg} \times 0.521 \mathrm{~kg} / \mathrm{s}=-1176$

$\mathrm{kW}$

Latent heat of vaporization for process $11 \mathrm{w}$

Specific latent heat of vaporization of water $\times$ Process $11 \mathrm{w}$ Mass Flow Rate $=2257 \mathrm{~kJ} / \mathrm{kg} \times 0.417 \mathrm{~kg} / \mathrm{s}=-941$

$\mathrm{kW}$

The total latent heat for the three processes was added to the heating load requirements on Table 4.1.

Total heating load requirements $=2.772 \mathrm{MW}$

Total cooling load requirements $=0.329 \mathrm{MW}$

In order to ensure maximum recovery of heat from the cooling processes during design of a heat exchange network, the temperatures for $T_{i}$ and $T_{f}$ were altered by adding or subtracting $0.5 \Delta T_{\min }$. The $T_{i}$ and $T_{f}$ for the processes that require heating were increased by a value of $0.5 \Delta \mathrm{T}_{\min }$. The temperature values for the processes that require cooling were reduced by $0.5 \Delta \mathrm{T}_{\min }$ [4]. Reference [5] recommends that the $\Delta \mathrm{T}_{\min }$ for processes that involves steam and hot air should be $10^{\circ} \mathrm{C} .0 .5 \Delta \mathrm{T}_{\min }$ is $5^{\circ} \mathrm{C}$. Table 4.2 shows the shifted temperature ranges for all the processes. From Table 4.1, the data collected from process 1 was $\mathrm{T}_{\mathrm{i}}=26{ }^{\circ} \mathrm{C}$ and $\mathrm{T}_{\mathrm{f}}=160{ }^{\circ} \mathrm{C}$. The altered temperature for process 1 is $\mathrm{T}_{\mathrm{i}}=31^{\circ} \mathrm{C}$ and $\mathrm{T}_{\mathrm{f}}=165^{\circ} \mathrm{C}$. The same alteration was applied on the other processes, increasing the temperature of the processes that need heating by $5^{\circ} \mathrm{C}$ and reducing the temperature of the streams that need cooling by $5^{\circ} \mathrm{C}$.

Table 4.2: Altered temperature intervals for the processes

\begin{tabular}{|l|l|l|l|l|l|l|l|l|l|l|l|l|l|}
\hline Process & $\mathbf{1}$ & $\mathbf{2}$ & $\mathbf{3 w}$ & $\mathbf{3 s}$ & $\mathbf{4}$ & $\mathbf{5}$ & $\mathbf{6}$ & $\mathbf{7}$ & $\mathbf{8}$ & $\mathbf{9}$ & $\mathbf{1 0}$ & $\mathbf{1 1 w}$ & $\mathbf{1 1 s}$ \\
\hline $\mathrm{T}_{\mathrm{i}}{ }^{\circ} \mathrm{C}$ & 31 & 198 & 31 & 105 & 563.3 & 522.3 & 579.7 & 478.7 & 451.3 & 193.6 & 29 & 31 & 105 \\
\hline $\mathrm{T}_{\mathrm{f}}{ }^{\circ} \mathrm{C}$ & 165 & 3 & 105 & 208.90 & 522.3 & 446.7 & 446.0 & 455 & 197.8 & 23.3 & 34 & 105 & 165 \\
\hline
\end{tabular}

The altered temperature ranges were arranged in a descending order as shown in Figure 4.1(shown in the next page). The diagram gives a pictorial presentation of the possibility of heat recovery between processes. Each 
arrow represents a heating or a cooling process in the sulphonation plant. The red arrows represent the processes that need cooling. The blue arrows represent the processes that need heating. The initial point of each arrow indicates the shifted initial temperature. The end point of each arrow indicates the shifted final temperature of the process.

In each temperature interval, there is a heat deficit, a heat surplus or a net exchange of heat [6]. For instance, in the interval of 478.7-455, there is a possible recovery of heat from processes 5, 6 and 7. Given that there are no heating processes in this interval, the heat within the interval will be positive. The net heat within the temperature interval of 478.7-455 was calculated as shown:

$$
(478.7-455) \times\left(\mathrm{Cp} \text {. } \dot{\mathrm{m}} \text { of process } 7+\mathrm{C}_{\mathrm{p}} \text {. } \dot{\mathrm{m}} \text { of process } 5+\mathrm{C}_{\mathrm{p}} \text {. } \dot{\mathrm{m}} \text { of process } 6\right)
$$

$$
(478.7-455) \times(0.354+0.688+0.679)=40.78 \mathrm{~kW}
$$

This implied that in the 478.7-455 temperature interval, a heat surplus of $40.78 \mathrm{~kW}$ was to be removed. Such a surplus can only be removed by use of an external cooling load or by using it to heat another process, by use of a heat exchanger.

In the temperature interval of $105-34$, there are processes 1, 2, 3w, 9 and $11 w$. Processes $1,3 w$ and $11 w$ require heating

$\begin{array}{llllll}\text { Whileprocesses } & 2 & \text { and } & 9 & \text { require } & \text { cooling. }\end{array}$ $1,3 \mathrm{w}$ and $11 \mathrm{w}$ have a heat deficit while processes 2 and 9 have a heat surplus. The net heat in the interval was calculated as shown:

$(105-34) \times\left(C p . \dot{m}\right.$ of process $9+C_{p}$. $\dot{m}$ of process $2-C_{p} \cdot \dot{m}$ of process $1-C_{p} \cdot \dot{m}$ of process $11 \mathrm{w}-C_{p} \cdot \dot{m}$ of process $3 \mathrm{w})$

$=(105-34) \times(0.107+0.445-0.957-1.743-2.178)=-307.146 \mathrm{~kW}$

This implied that in the temperature interval of $105-34$, there was net heat deficit of 307.146kW. Such a deficit can only be met by supply of an external heating load or by recovering heat from the other processes that need cooling.

These computations were carried out on all the other intervals as shown in Table 4.3. The $\left(\sum \mathrm{Cp}_{\mathrm{h}} \cdot \dot{\mathrm{m}}-\sum \mathrm{Cp} \cdot \dot{\mathrm{m}}\right)$ indicates the difference between the heat capacity flow rate of the heating processes and the cooling processes in each interval. $\Delta \mathrm{H}_{\mathrm{i}}(\mathrm{kW})$ is the net heat in each interval. The cumulative heat column shows addition of heat from the higher temperature intervals to the lower intervals. The surplus heat in the higher intervals is transferred to the lower temperature intervals that have heat deficit. The minimum required external heat load is read off from where the cumulative heat is negative. The pinch temperature coincides with the point of the negative cumulative heat value [1]. 


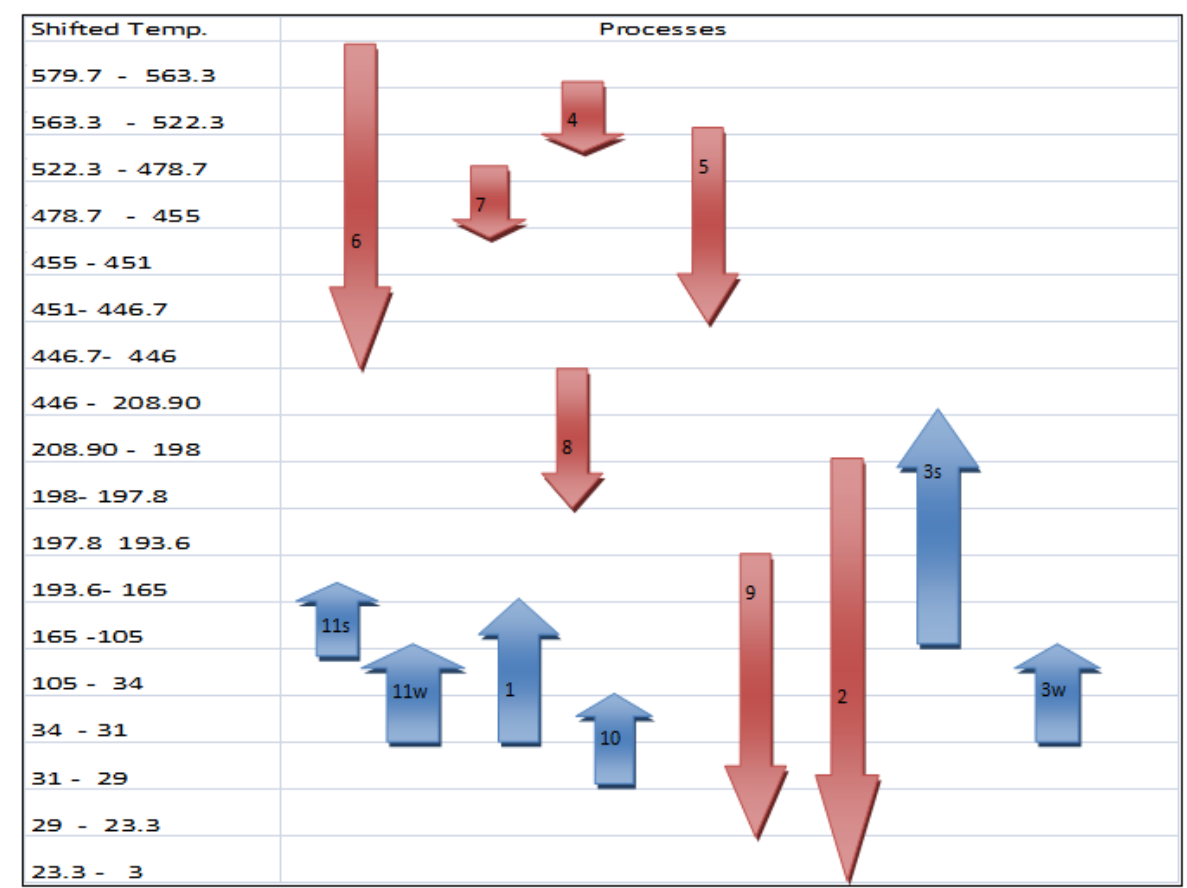

Figure 4.1: Graphical Presentation of Possible Heat Recoveries within Intervals.

Table 4.3: Temperature interval Energy Targeting Table

\begin{tabular}{|l|l|l|l|l|}
\hline Shifted Temp. & Temp. Difference & $(\Sigma$ Cph.m $-\Sigma$ Cpc. $\dot{m})$ & $\Delta \mathrm{Hi}(\mathrm{kW})$ & Cummulative $\Delta \mathrm{Hi}(\mathrm{kW})$ \\
\hline $579.7-563.3$ & 16.4 & 0.679 & 11.1356 & 11.1356 \\
\hline $563.3-522.3$ & 41 & 1.485 & 60.885 & 72.0206 \\
\hline $522.3-478.8$ & 43.5 & 1.367 & 59.465 & 131.4856 \\
\hline $478.7-455.0$ & 23.7 & 1.721 & 40.788 & 172.2736 \\
\hline $455-451.3$ & 3.7 & 1.367 & 5.06 & 177.3336 \\
\hline $451.3-446.7$ & 4.6 & 1.367 & 6.29 & 183.6236 \\
\hline $446.7-446.0$ & 0.6 & 0.679 & 0.4074 & 184.031 \\
\hline $446.0-208.9$ & 237.1 & 0.151 & 35.8 & 219.831 \\
\hline $208.9-198$ & 10 & -0.938 & -9.38 & 210.451 \\
\hline $198.0-197.8$ & 0.2 & -0.493 & -0.0986 & 210.3525 \\
\hline $197.8-193.6$ & 4.2 & -0.644 & -2.705 & 207.6475 \\
\hline $193.6-165.0$ & 28.6 & -0.537 & -15.36 & 192.2875 \\
\hline $165.0-105.0$ & 60 & -2.366 & -212.7 & -20.41 \\
\hline $105.0-34.0$ & 71 & -4.326 & -2424.16 & -2444.57 \\
\hline $34.0-31.0$ & 3 & -2.863 & -11.472 & -2456.0445 \\
\hline A minimum external heat supply of 2.46 $\mathrm{mW}$ is required. & & \\
\hline $31.0-29.0$ & 2 & 1.054 & 2.108 & 2.108 \\
\hline $29.0-23.3$ & 5.7 & 0.552 & 3.146 & 5.254 \\
\hline $23.3-3.0$ & 20.3 & 0.445 & 9.034 & 14.288 \\
\hline
\end{tabular}


Table 4.3 shows the energy targets in the sulphonation plant at Orbit Chemical Industries.

The minimum required external heating load is $2.456 \mathrm{MW}$.

The minimum required external cooling load is $0.014 \mathrm{MW}$.

The maximum internal recoverable energy is computed by

Total heating requirements- Minimum required external heating load [6].

$2.772-2.456=0.316 \mathrm{MW}$

Or

Total cooling requirements - Minimum required external cooling load $=0.329 \mathrm{MW}-0.014=0.315 \mathrm{MW}$

The maximum internal recoverable energy is $0.32 \mathrm{MW}$

The temperature at the point where the external supply of heat is required is called the pinch temperature. The pinch temperature for the process was $31^{\circ} \mathrm{C}$.

\subsection{Network Design}

A heat exchange network was designed to meet the calculated targets. Hot streams were matched with cold streams for internal recovery of heat. The Second Law of Thermodynamics was used to calculate heat recovery between hot and cold streams. The matching of the hot and cold streams began from the pinch point [1]. Table 4.3 used the shifted temperatures for energy targeting. For the network design, the real temperatures were used. The pinch temperature for the cold streams was taken as $(31-5){ }^{\circ} \mathrm{C}$ while the pinch temperature for the hot streams was taken as $(31+5){ }^{\circ} \mathrm{C}$. This operation was due to the fact that during the altering of the temperatures, the cold streams were increased by $5{ }^{\circ} \mathrm{C}$ while the hot streams were reduced by $5{ }^{\circ} \mathrm{C}$. The stream matching was split in two sections. The cold streams were split at $26{ }^{\circ} \mathrm{C}$ while the hot streams were split at $36{ }^{\circ} \mathrm{C}$. During the matching, care was taken to avoid adding an external cooling load at temperatures above $36{ }^{\circ} \mathrm{C}$. Likewise, care was taken not to add any external heating load at temperatures below $26^{\circ} \mathrm{C}$. Violation of these two rules would lead to addition of unnecessary cooling and heating requirements [7]. However, where design constrains did not allow the rules to be observed, a tradeoff was carried out. For any possible recovery between the hot and the cold streams, there should be a minimum temperature difference of $10{ }^{\circ} \mathrm{C}$, the $\Delta \mathrm{T}_{\min }[5]$. External supply of heat was applied to the cold streams and an external cooling load was applied to the hot streams below $36{ }^{\circ} \mathrm{C}$. Recovery between the cold and the hot streams was only possible at temperatures above $36{ }^{\circ} \mathrm{C}$. This was a violation but it was necessitated by the design constrains because no recovery was possible below the pinch point. The following examples show the matching process for the hot and the cold streams.

For stream 1 to change its temperature from $26^{\circ} \mathrm{C}$ to $36^{\circ} \mathrm{C}$, an external heating load was to be applied. The load was calculated as shown below:

$0.957(36-26)=9.57 \mathrm{~kW}$

Stream 6 could be matched to stream 1. Stream 6 would transfer $(584.7-451.0) \times 0.679=90.78 \mathrm{~kW}$. This would increase the temperature of stream 1 by a value $\Delta T_{1} ; 0.957\left(\Delta T_{1}\right)=90.78$

$\Delta \mathrm{T}_{1}=94.86{ }^{\circ} \mathrm{C}$.

Temperature of stream 1 would change to $(36+94.86)=130.86^{\circ} \mathrm{C}$.

Stream 7 would be matched to stream 1

It would transfer $(483.7-460) \times 0.354=8.39 \mathrm{~kW}$ to stream 1 . Stream 1 would change its temperature by value of $\Delta \mathrm{T}_{1}$;

$0.957\left(\Delta \mathrm{T}_{1}\right)=8.39$

$\Delta \mathrm{T}_{1}=8.8{ }^{\circ} \mathrm{C}$. Stream 1 will change its temperature to $(130.86+8.8)=139.66{ }^{\circ} \mathrm{C}$.

Stream 1 needed to change its temperature from $140{ }^{\circ} \mathrm{C}$ to $160{ }^{\circ} \mathrm{C}$. An external heating load was needed. This was calculated by; $(160-140) \times 0.957=19.14 \mathrm{~kW}$. At $115^{\circ} \mathrm{C}$, sulphur in stream 1 melts at constant temperature. 
Latent heat of fusion is required. An external heat load will supply the latent heat. Latent heat of fusion was calculated as $70.74 \mathrm{~kW}$. Total external heating load requirement is $19.14 \mathrm{~kW}+70.74 \mathrm{~kW}=89.88 \mathrm{~kW}$. The external heating load would elevate the temperature of stream 1 from $140{ }^{\circ} \mathrm{C}$ to $160{ }^{\circ} \mathrm{C}$.

The matching was carried out on all the streams and a heat exchange network diagram constructed as shown in

figure 4.2. The red horizontal lines represent the hot streams. The blue horizontal lines represent the cold streams. The blackvertical lines connecting between streams represent heat exchangers. The numerals at the end of each heat exchange show the entrance temperature of the material. For example, between stream 8 and stream $11 \mathrm{w}$, the vertical line runs from 36 to 456 . This means that a heat exchanger will be used to recover heat from stream 8 to heat stream $11 \mathrm{w}$. The entry temperature of stream $11 \mathrm{w}$ will be $36{ }^{\circ} \mathrm{C}$ while the entry temperature for stream 8 will be $456{ }^{\circ} \mathrm{C}$. The exchange will elevate the temperature of $11 \mathrm{w}$ to $58{ }^{\circ} \mathrm{C}$. An external heating load will heat the stream from $58{ }^{\circ} \mathrm{C}$ to the final required temperature of $100{ }^{\circ} \mathrm{C}$. The red circles show the temperature points at which the external heating loads will be applied. The blue circles show the temperature points at which the external cooling loads will be applied. The final required temperature values are shown in

Table 4.1

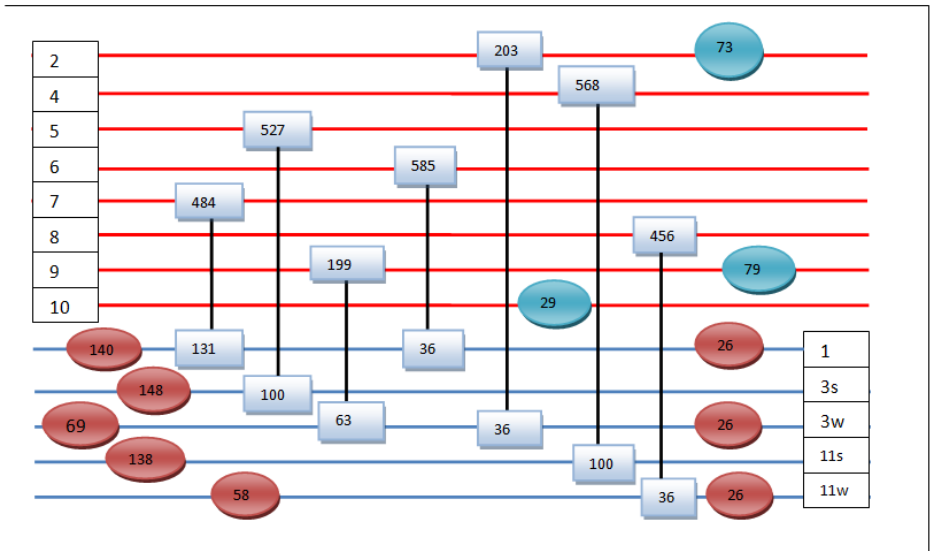

\section{Figure 4.2: Heat Exchange Network Diagram}

The external heating loads required for the streams

Stream 1

$9.57 \mathrm{~kW}$ added to the stream at $26{ }^{\circ} \mathrm{C}$ and $89.88 \mathrm{~kW}$ at $140{ }^{\circ} \mathrm{C}$

Stream $3 \mathrm{~s}$

$61 \mathrm{~kW}$ added to the stream at $148{ }^{\circ} \mathrm{C}$.

Stream $3 \mathrm{w}$

$21.78 \mathrm{~kW}$, added to the stream at $26{ }^{\circ} \mathrm{C}, 68.61 \mathrm{~kW}$ at $69{ }^{\circ} \mathrm{C}$

and $1176 \mathrm{~kW}$ at $100^{\circ} \mathrm{C}$.

Stream $11 \mathrm{w}$

$17.43 \mathrm{~kW}$ added to the stream at $26{ }^{\circ} \mathrm{C}, 73.21 \mathrm{~kW}$ at $58{ }^{\circ} \mathrm{C}$ and $941 \mathrm{~kW}$ at $100{ }^{\circ} \mathrm{C}$.

Stream $11 \mathrm{~s}$

$19.184 \mathrm{~kW}$ added at $138{ }^{\circ} \mathrm{C}$.

Stream 2

A cooling load of $21 \mathrm{~kW}$ at $73{ }^{\circ} \mathrm{C}$

Stream 9

A cooling load of $5.67 \mathrm{~kW}$ at $79{ }^{\circ} \mathrm{C}$

Stream 10

An external cooling load of $2.51 \mathrm{~kW}$ at $29{ }^{\circ} \mathrm{C}$ 
Total external heating load provided for by the network is $2.477 \mathrm{~mW}$. The targeted minimum external heating load was $2.456 \mathrm{~mW}$. The difference is due to the energy penalty, caused by the addition of the external heating loads below the pinch point. The total external cooling load in the exchange network is $0.0292 \mathrm{MW}$. The targeted minimum external cooling load was 0.014 MW. Addition of external cooling load above the pinch point led to this difference[1].

\subsection{Investment Appraisal}

An appraisal was carried out by calculating the energy savings that would be made if the new design was to be implemented. In the calculation, the recoverable energy was used to estimate the costs that would be saved if the design was to be implemented. The heating utility demand of the plant, without the retrofit, was $2.772 \mathrm{~mW}$. It costs the company an average of KShs 27475200 between the utility demands and the cost. The savings were computed as

$(0.316 \div 2.772) \times 27475200=$ KShs 3132093 per year.

The cost of implementing the retrofit depends on the total surface area of heat exchanger. The modeling was done by taking into account the materials used for heat exchangers. The factory heat exchangers are made of Stainless Steel Grade 304L[8]. The surface area of the exchangers was calculated. From Equation 2.8, area of heat exchanger was calculated by:

$$
\mathrm{A}=\mathrm{Q}_{\mathrm{t}} \div(\mathrm{U} \times \mathrm{LMTD})
$$

$\mathrm{Q}_{\mathrm{t}}$ is the heat that should be transferred between the hot and cold streams

$$
\operatorname{LMTD}=\left(\Delta \mathrm{T}_{\text {en }}-\Delta \mathrm{T}_{\mathrm{ex}}\right) \div \ln \left(\Delta \mathrm{T}_{\mathrm{en}} \div \Delta \mathrm{T}_{\mathrm{ex}}\right)
$$

$\Delta \mathrm{T}_{\mathrm{en}}$ is the temperature difference between entry points of cold and hot streams.

$\Delta \mathrm{T}_{\mathrm{ex}}$ is the temperature difference between exit points of cold and hot streams.

$\mathrm{U}$ is the overall heat transfer coefficient [9].

The formula was used to calculate the area of the heat exchangers between each of the recovery points on the network. Total heat exchanger area was calculated as $627.57 \mathrm{M}^{2}$. This costs KShs 49275540 inclusive of implementation costs. Implementation of the retrofit design would result in annual saving of KShs 3132093 with a simple payback period is 14 years.

\section{Conclusion and Recommendation}

This work has shown that the sulphonation process at Orbit Chemicals Industries has theoretical maximum recoverable energy of $0.316 \mathrm{MW}$, theoretical minimum external heating load requirement of $2.456 \mathrm{MW}$ and a theoretical minimum cooling load of 0.014 MW. These values can be put in comparison with the current utilities demand of 2.772 MW and 0.329 MW for heating load and cooling load requirements respectively. This means that $96.6 \%$ of the cooling demand and $11.4 \%$ of the heating demand could be saved if a design meeting these targets was to be implemented with the minimum demands in consideration. The investment decisions that peg on the simple payback period may not favor the full implementation of the decision. However, some parts of the design can be implemented, leading to considerable savings. The whole design can be implemented when the company is carrying out a retrofit or a plant expansion exercise.

The design has 7 heat exchangers, 7 external heating loads and 3 external cooling loads. Implementation of the energy recovery network design was found to cost KShs 49275540 and would enable the company to make savings of KShs 3132093 per year. The project will have a simple payback period of 14 years. The retrofit design can be implemented in part or wholly. 
The plant survey for the research was for one week. In order to come up with detailed network design, it is recommended that future research consider taking more time than one week to do plant survey. Maximum energy recovery can be realized if pinch analysis combined heat and water. For optimum results, water pinch analysis should be done alongside heat pinch analysis. This would help to obtain maximum recovery electrical and fossil energy used in the plant.

\section{References}

[1] Kemp, I. C. (2011). Pinch analysis and process integration: a user guide on process integration for the efficient use of energy. Butterworth-Heinemann.

[2] Svensson, E\& Harvey, S (2011). Pinch Analysis of a Partly Integrated Pulp and Paper Mill. World Renewable Energy Congress, 2011- Linkopin, Sweden, 8-13.

[3] Festin, M \& Mora, V (2009). Pinch analysis of the Norske Skog Skogn TMP mill. Master's Thesis within the Sustainable Energy Systems and Innovative and Sustainable Chemical Engineering programmes. Chalmers University Of Technology, Göteborg, Sweden 2009 (Unpublished).

[4] Dunn, E \& El-Halwagi (2003). Process integration technology review: background and applications in the chemical process industry. Journal of Chemical Technology and Biotechnology.volume 78 pages 1011-1021.

[5] Natural Resources Canada, (2003). Pinch Analysis: For the Efficient use of Energy, Water and Hydrogen. Natural Resources, Canada.

[6] Linnhoff, M (1998). Introduction to Pinch Technology.Targeting House, UK.

[7] Linnhoff, B., Towsend, D. W., Boland, D., Hewitt, G. F., Thomas, B. E. A., Guy, A. R.,Marsland, R. H.(1982). A User Guide on Process Integration for the Efficient Use of Energy. The Institution of Chemical Engineers, Rugby.

[8] Thulukkanam, K. (2013). Heat Exchanger Design Handbook.CRC Press.

[9] Shenoy,U (1995). Heat Exchanger Network Analysis; Process Optimization by Energy and Resource Analysis.Gulf Publishing House, Houston, Texas. 